\title{
Comprehensive assessment of the degree of landscape compositions' ornamentality
}

\author{
Olga Emelyanova*, Lubov Masalova, and Andrey Firsov \\ Russian Research Institute of Fruit Crop Breeding (VNIISPK), 302530 Oryol, Russian Federation
}

\begin{abstract}
Plantings' ornamentality is an important aspect of the aesthetic appearance formation of urbanized landscapes. In urban ecosystems, trees and shrubs are often exposed to high stress levels that shortens their lifespan and reduces ornamentality. Plant introduction is one of the methods of enriching the assortment with resistant species. The aim of the research was to comprehensively assess the ornamentality degree of North American introduction tree groups from the genetic collection of the All-Russian scientific research Institute of Fruit Crop Breeding (VNIISPK) arboretum and to give recommendations on improving their composition. Research was carried out in 2013-2019, taking into account the dynamics of changes in decorative qualities during the year. Throughout the year, landscape compositions showed peaks of ornamentality in the same seasons of the year (May, September). To give dynamism to groups in the summer period, it is recommended to plant Spiraea douglasii in the 1st group; in composition 2 - Hydrangea arborescens and two varieties of Physocarpus opulifolius: 'Darts Gold' and 'Summer Wine'. Graphics of ornamentality degree changes of landscape groups are recommended to be used when drawing up landscape groups for various purposes to ensure their ornamentality during either an entire year or a certain period.
\end{abstract}

\section{Introduction}

Having unique properties to improve the state of human habitat, green plantings play a significant role in the formation of ecological comfort of urban ecosystems, and plantings' ornamentality is an important aspect of the formation of urbanized landscapes' aesthetic appearance. The higher the decorative qualities of plants, the more expressive and attractive landscape construction objects look [1-3]. Ornamentality is the concept of aesthetic, and, therefore, is subjective. However, it is always possible to distinguish certain qualitative and quantitative characteristics that are measurable [4]. The general plants' ornamentality is a complex of a large number of external features (decorative qualities). Among them are: the size and shape of the crown; the nature of stem branching and bark texture; the structure, color and autumn coloring of the leaves; the size and color of flowers, inflorescences and fruits. It is also important to consider the abundance and duration of flowering, as well as the duration of the ornamentality period in general. It should be noted that all the listed plants' traits are variable during the lifetime and each growing season [4-8]. At the same time,

\footnotetext{
${ }^{*}$ Corresponding author: dendrariy@vniispk.ru
} 
decorative qualities depend not only on the genotypic and phenotypic features of the plant, but also on the environment in which they grow $[4,8,9]$.

In urbanized landscapes, trees and shrubs are often exposed to high stress levels (shading, drought, air and soil pollution), shortening the duration of their life and reducing ornamentality. Street plantings are subject to a particularly strong influence. Woody plants of parks and squares [9-13] are affected to a lesser extent. Not all plant species and their forms have sufficient adaptability to unfavorable conditions of urban abiotic and biotic environment, anthropogenic pressure. Often, unsustainable species do not meet aesthetic requirements and are unable to maintain ornamentality throughout the year. Currently, scientists are actively working on the creation of a sustainable assortment of ornamental woody plants to be used in habitat-forming and environment-improving phytotechnologies [14-16]. Plant introduction is one of the main methods of range enrichment [17-19]. In the process of woody plants' introduction, it is often necessary to assess the ornamentality degree in order to recommend them for use at certain landscaping objects [4, 6, 14].

Along with a complex of decorative qualities, each species, form or variety of woody plants is dominated by one main quality indicating the nature of use in certain compositions. In large groups and arrays, the main role is most often played by the size or shape of the crown; for small groups, the main traits are the shape or color of leaves, the nature of flowering, etc. $[4,20]$. Therefore, in the process of creating new landscape groups and reconstruction of existing ones, it is important to assess the aesthetic attractiveness not only for each plant separately, but also of all compositions as a whole [3].

To date, the genetic collection of the All-Russian Research Institute of Fruit Crop Breeding (VNIISPK) arboretum has more than 310 species, forms and varieties [18, 21]. The arboretum is located in the European part of Russia $368 \mathrm{~km}$ southwest of Moscow $\left(53^{\circ} 00^{\prime} \mathrm{N}\right.$, $36^{\circ} 00^{\prime} \mathrm{E}$ ), one and a half kilometers from Oryol city in the immediate vicinity from the busy route Oryol-Bolkhov, from which it is separated by a single-row Tilia cordata planting. The plant collection is arranged by geographical principle. Due to climate and soil conditions" similarity of the Russian midland and North America, this arboretum zone is one of the most promising in introduction aspect $[17,22]$. Observations of the manifestation of woody plants' ornamental traits are carried out both individually for each plant species and for landscape groups as a whole. The purpose of these studies is to comprehensively assess the ornamentality degree of the two wood groups of the North American zone and to provide recommendations for improving their composition.

\section{Materials and methods}

The subjects of the study were two landscape groups of the North American zone out of the genetic collection of the VNIISPK arboretum (table 1). Assessment of the ornamentality degree of plants in groups was carried out for 7 years (2013-1019) according to the method of complex assessment of wood plants' ornamentality degree considering the dynamics of decorative qualities change during the year $[4,14]$. According to this method, a monthly assessment of wood plants was carried out to account for the dynamics of seasonal changes in the ornamentality degree by six traits: crown architectonics, leaves (needles), flowers and inflorescences (blossom dust), fruits (cones), bark coloration and texture, originality. A fivepoint scale is used for evaluation, where 5 is the highest value. If a trait is absent (for example, flowers in winter), then " 0 " score is placed in the corresponding column. A score of " 0 " is also set if any trait, for example, no fallen leaves in winter, reduces the decorative effect of the plant. In the presence of such a negative trait in the corresponding months, a score of " 0 " is set in "originality" line. When assessing the decorative qualities of leaves (needles), not only their shape and color, but also the severity of leaf mosaic was considered. If plants have an unusual shape of crown, leaves or flowers, this is considered according to the "originality" 
criterion $[4,14]$. We determine the ornamentality degree for each trait on a monthly basis and multiply it by weight coefficients according to the method. Graphs are built according to sums of products at the end of the year, which allow to analyze the variability of the ornamentality degree of the species (form, variety) during the year [4, 14].

Table 1. Objects of study

\begin{tabular}{|l|c|}
\hline Type & Number of specimens per group \\
\hline \multicolumn{2}{|c|}{ Group 1 } \\
\hline Quercus rubra L. & 3 \\
\hline Juglans rupestris Engelm. & 3 \\
\hline Picea canadensis Britt. & 13 \\
\hline Picea pungens f. glauca Reg. & 3 \\
\hline Chamaecyparis pisifera (Sieb.et Zucc.) Endl. & 3 \\
\hline Berberis ottavensis f. purpurea Schneid & 5 \\
\hline \multicolumn{2}{|c|}{ Group 2 } \\
\hline Pseudotsuga menziesii f. glauca Schneid. & 6 \\
\hline Picea pungens f. glauca Reg. & 4 \\
\hline Picea Engelmanii (Parry)Engelm. & 1 \\
\hline Betula lenta L. & 1 \\
\hline
\end{tabular}

\section{Results and discussion}

Group 1 consists of 30 plants of six species and forms. On the chart (fig. 1) the dynamics of changes in ornamentality degree throughout the year for all objects is well traced. Ornamentality degree analysis of the group's representatives shows that since Picea pungens f. glauca is an evergreen plant, it has a high ornamentality degree throughout the year and a dense geometrically correct cone-shaped crown and bluish needle coloration. From November to March during a period of relatively low ornamentality degree of other group components, Picea pungens f. glauca is an accent attracting observers' views. In the rest of the months, it is the backround for other plants. Chamaecyparis pisifera has a low ornamentality degree throughout the year and is a background for other plants due to evergreen needles.

The group had high ornamentality degree from April to October with peaks in May and September. The first surge is observed due to the blossoming start of light green needles against the background of dense silvery-gray texture of the Picea canadensis crown, bright purple color of Berberis ottavensis f. purpurea young foliage and crown openness, which is observed during the beginning of leaf growth, Quercus rubra and Juglans rupestris. The second peak (the highest) was recorded in September. It is due to the manifestation of leafbearing plants' autumn coloring: golden-red tones in Berberis ottavensis f. purpurea, brownish red in Quercus rubra and golden yellow in Juglans rupestris (Fig. 3, A). 


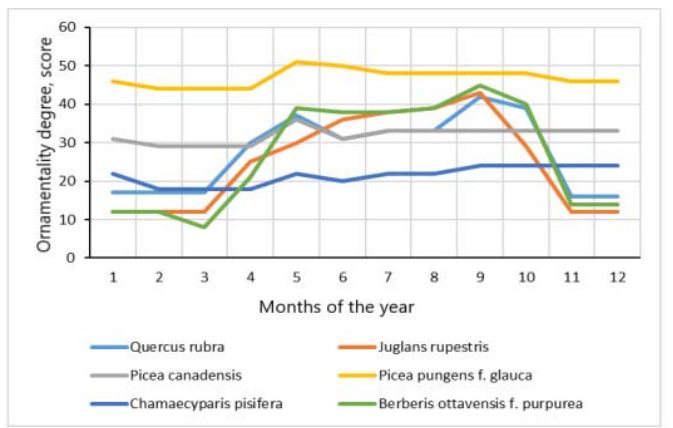

Fig. 1. Dynamics of changes in ornamentality degree of landscape group No. 1

Complex analysis of the ornamentality degree of group No. 1 as a whole shows that from November to March there are dominants in its appearance in the form of conifers and a small accent formed by spreading arcuate bright brown branches of Berberis ottavensis f. purpurea. In the summer, the landscape composition has a high general ornamentality. But accents in the form of flowering shrubs can make this group more dynamic.

When selecting plants, it is necessary to strive for that when their charts are superimposed on each other, there are ornamentality peaks of at least one species in most months of the year. At the same time, it is undesirable that all or most plants in the same group show maximum ornamentality in the same period with different colors of flowers and leaves (needles). This will lead to excessive color diversity, which will impair perception and can cause a person's nervousness and tension. While in the rest of the months, the landscape composition will not look attractive [4]. Based on this, to increase ornamentality of group No. 1, we recommend one variety: Spiraea douglasii Hook. with dark pink flowers in dense narrow-pyramidal, apical, paniculate inflorescences. This species blooms in July-August when there are no ornamentality peaks on the chart (fig. 1).

Landscape group No.2 consists of 12 plants of four species and forms. The bulk of the group is coniferous plants, which could not but affect the overall picture of ornamentality degree (fig. 2). A lack of dynamism is well traced on the chart. Being a leaf-bearing plant, only Betula lenta changes its appearance due to bright yellow male inflorescences, leaf blossoming start in April and changing the foliage color from green to golden yellow in September-October (Fig. 3, B). Being generally highly ornamental, coniferous plants in this group practically do not change during the seasons of the year. Small differences can be seen only in May, when young needles unfold.

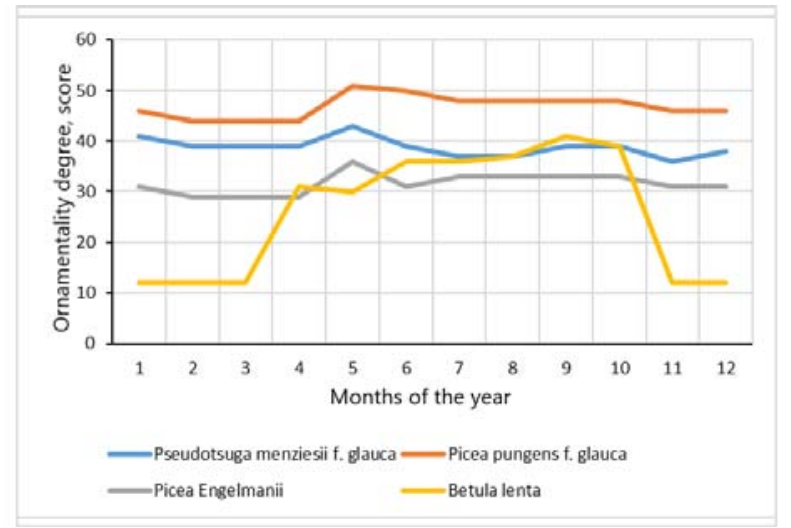

Fig. 2. Dynamics of changes in ornamentality degree of landscape group No.2 
To make group No.2 more dynamic and interesting for perception, it is necessary to add deciduous shrubs to it. We recommend Hydrangea arborescens L. Its sprawling crown shape will match well with the Betula lenta oval crown, and large thyroid inflorescences of white flowers blooming from July to October, will be shaded by bluish color of Pseudotsuga menziesii f. glauca and Picea pungens $f$. glauca needles. Also, it is recommended to plant two varieties of Physocarpus opulifolius (L.) Maxim.: 'Darts Gold' with golden yellow and 'Summer Wine' with purplish-red foliage color in this landscape group. The similarity in architectonics and texture of these varieties' crown will allow to focus on color and highlight them against the background of bluish and green tones of other species' foliage.
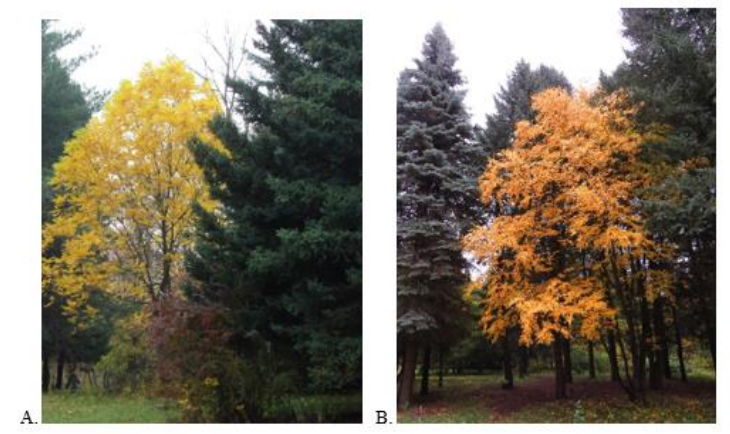

Fig. 3. Autumn coloring of landscape groups' plants: A - Group 1; B - Group 2

\section{Conclusion}

Comprehensive ornamentality degree assessment of two North American zone tree groups of the VNIISPK arboretum genetic collection revealed that both landscape compositions show ornamentality peaks in the same periods of the year (May, September), but they are not sufficent for year-round appeal. Group No.1 includes a larger number of species and forms that have different decorative traits compared to Group No. 2.

To give dynamism to groups in summer, it is recommended to plant shrubs: in group No. 1, it is required to add Spiraea douglasii; in the landscape composition No. 2 it is recommended to plant Hydrangea arborescens and two varieties of Physocarpus opulifolius : 'Darts Gold' and 'Summer Wine'.

According to the research results, it was revealed that charts of landscape groups' ornamentality level degree change should be used in the future in the preparation of landscape groups of different purposes to ensure their ornamentality throughout the year or at a certain period. Also, these charts will be useful in the design of continuous flowering gardens.

\section{References}

1. O.Yu. Emelyanova, A.N. Firsov, Coll. Of scient. works of the State Nikitskiy botanical garden, 146, 224 (2018)

2. G.A. Yapryntseva, Bulletin of the Altay State Agrarian University, 160(2), 66 (2018)

3. M.V. Larionov, N.V. Larionov, I.S. Siraeva, T.S. Gromova, V.V. Soldatova, E.A. Logacheva, IOP Conf. Series: Earth and Environmental Science, 421(8), 082002 (2020)

4. O.Yu. Emelyanova, Contemporary horticulture, 3(19), 54 (2016)

5. O.Yu. Dubovitskaya, E.V. Zolotareva, Bulletin of OryolGAU, 23(2), 72 (2010) 
6. Zh. H. Vardanyan, Papers of the National Science Academy of Armenia, 117(4), 340 (2017)

7. K. Karlović, N. Jeran, D. Dujmović Purgar, V. Židovec, S. Bolarić, A. Vokurka, Acta Horticulturae, 1288, 75 (2020)

8. 8.A.I.Kolesnikov, Decorative dendrology, Forest industry, 703 (1974)

9. O.Y. Dubovitskaya, E.V. Zolotareva, Scientific Bulletin of the Belgorod State University, Natural sciences, 29(194, 23), 38(2014)

10. A. Sæbo, Z. Borzan, C. Ducatillion, A. Hatzistathis, T. Lagerström, J. Supuka, J. L. García-Valdecantos, F. Rego, J. V. Slycken, Urban Forests and Trees, 257 (2005)

11. P.K. Rai, Ecotoxicology and Environmental Safety, 129, 120 (2016)

12. O.Yu. Emelyanova, L.I. Masalova, Contemporary horticulture, 4(24), 113 (2017)

13. J. Vieira, P. Matos, T. Mexia, P. Silva, N. Lopes, C. Freitas, O. Correia, M. San-tosReis, C. Branquinho, P. Pinho, Environmental Research, 160, 306 (2018)

14. S.D. Knyzev, O.Yu. Emelyanova, O.D. Golyaeva, 188 (2019)

15. L. Salvati, C. Ferrar, A. Mavrakis, A. Colantoni, Journal of Forestry Research, 27(1), 175 (2016)

16. M.A. Taysumov, M.U. Umarov, M.A.-M. Astamirova, A.S. Abdurzakova, R.S. Magomadova, S.A. Israilova, B.A. Khasueva, K.L. Khalidova, South of Russia: Ecology, Development, 13(1), 73 (2018)

17. O.Yu. Dubovitskaya, L.I. Masalova, Contemporary horticulture, 4(8), 80 (2013)

18. O.Yu. Dubovitskaya, M.F. Tsoy, G.A. Pavlenkova, L.I. Masalova, A.N. Firsov, Contemporary horticulture, 2(14), 111 (2015)

19. Ya.A. Krekova, S.V. Zalesov, N.K. Chebot'ko, Pomiculture, seed farming, woody plants' introduction, 20, 89 (2017)

20. L.I. Rubtsov, Trees and shrubs in landscape architecture, 272 (1977)

21. O.Yu. Emelyanova, A.N. Firsov, L.I. Masalova, Selection and variety breeding of horticultural crops, 5(2), 29 (2018)

22. E.V. Zolotareva, O.U. Dubovitskaya, Bulletin of OryolGAU, 41(2), 40 (2013) 